\title{
Use of online knowledge resources by prominent South African researchers
}

\author{
Reinhold Treptow' and Megan James ${ }^{2}$ \\ Centre for Research on Evaluation, Science and Technology; University of Stellenbosch \\ treptow@sun.ac.za; mjames@sun.ac.za
}

\begin{abstract}
Received: 16 March 2011
Accepted: 18 May 2011

The growth in online knowledge resources has transformed information securing practices and effects have been especially pronounced for scientific journals. It has therefore become increasingly necessary to understand researchers' information search and securing preferences. Leading South African researchers were indentified and invited to participate in a web $\square$ based survey to this end. Results indicate that electronic resources are favoured for journal articles, but not for books, and researchers commonly employ chaining and browsing behaviour to locate relevant journal articles. Full[text journals are favoured by researchers to undertake searches. These are favoured over other bibliographic databases and other federated searches (Google, Google Scholar and MetaLib). Analyses of the coverage of top rated journals by the two top rated full $\square$ text databases EBSCOhost and ScienceDirect reveals significantly lower coverage when compared with the coverage of top journals by the citation databases Scopus and Web of Science. Researchers should therefore make greater use of these resources to effectively locate relevant material.
\end{abstract}

Keywords: Online knowledge resources; electronic journals; information seeking; South Africa

\section{Introduction}

The conversion of hardcopy books and journal articles to the electronic format has significantly impacted the use of scientific literature by both the international and national research community. Full[text and bibliographic journal databases, in particular, have been widely adopted. Multi[journal search engines and citation databases have subsequently become indispensable tools used to locate and assess the relative impact of pertinent material. The increasing cost associated with the acquisition of electronic journals coupled with the seemingly endless growth in material available has prompted a need to understand the utilization requirements of researchers and assess the value of various databases. This study investigates the use of online knowledge resources by prominent South African researchers, with particular attention devoted to electronic journals. Before discussion of the study, methodology and results, an overview of relevant literature is presented. The literature review begins with a brief overview of the origin and development of electronic journals highlighting prominent trends. Thereafter the key attributes sought by electronic journal users are distinguished. The introduction of electronic journals and related resources has significantly affected the information seeking behaviour of researchers. Information seeking behaviour is thus defined and pertinent results of studies investigating electronic journal information seeking behaviour are presented. The review concludes with an overview of studies comparing various electronic full[text and bibliographic databases.

\section{Literature review}

Tenopir et al., (2003) distinguish three evolutionary phases in the development of electronic journal databases. The first, dubbed the "early systems phase", commenced around 1990 as journals were converted into CDROM format and introduced online. During this phase many scholars questioned the longevity of this format and doubts were expressed regarding the ability of scientists to uphold traditional measures of quality control and peer[review. Subsequently (and correspondingly) the "evolving system phase" followed in the late 1990's as libraries expanded their collections of electronic journals as a supplement to, and even substitute for, the printed form. This period was marked by innovative developments to facilitate the distribution of electronic journals. Aggregator databases were developed and licenses negotiated with publishers. A number of libraries also formed consortia in an effort to secure access to a greater volume of electronic journals. The current phase has been termed the "advanced system phase" marked by technological developments that include hypertext links to relevant information and information sources; availability of user[\$tatistics; advanced database search capabilities as well as federated search capabilities across various databases. During the course of this development a number of pervasive and salient trends have been distinguished by various authors (Tenner \& Zheng

I. Reinhold Treptow is a Researcher at the Centre for Research on Evaluation, Science and Technology; University of Stellenbosch, South Africa.

2. Megan James is a Researcher at the Centre for Research on Evaluation, Science and Technology; University of Stellenbosch, South Africa. 
1999; Rogers 2001; Dillon \& Hahn 2002; Institute for the Future 2002; Monopoli et al., 2002; Bar[lan, Peritz \& Wolman 2003; Tenopir 2003; Tenopir et al., 2003; Rowlands 2007). These include that:

- Electronic journals have displaced print at a rate that has been faster than anticipated.

- This trend is supported by the increasing use of bibliographic and full[text databases.

- Personal subscriptions to journals are decreasing as requests for separate copies of articles increase.

- The use of electronic journals was initially not indicative of the preference of users but rather due to availability of electronic copies; however, in more recent studies users commonly indicate a preference for the electronic format.

Various studies have also sought to uncover the key attributes sought in electronic journal resources (Tenner \& Zheng 1999; Rogers 2001; Dillon \& Hahn 2002; Institute for the Future 2002; Monopoli et al., 2002; Bar】lan, Peritz \& Wolman 2003; Tenopir 2003; Tenopir et al., 2003; Rowlands, 2007; Vibert et al., 2007; Voorbij \& Ongering, 2008). Studies reveal that researchers commonly prize: speed and ease of access to locate and download articles; ubiquitous access; access to large quantities of information; direct access to abstracts; retrieval of full[text articles; e[journal hyperlinks; effective browsing and search functions; direct access to and wide variety of limit options with regard to database searches; assistance in selecting the most relevant keywords; digital visibility (interface and text display); and greater choice in subscription and membership packages. Functions considered less important included discussion platforms, multimedia, saving of bibliographic data and alerts indicating new publications.

The aforementioned developments have significantly influenced the information seeking behaviour of researchers. Odongo and Mostert (2006) present a comprehensive definition of information seeking behaviour. Information seeking is "seen as a process with which humans engage to purposefully change their state of knowledge" (Odongo \& Mostert 2006: 147) and is described as the purposeful pursuit of knowledge that will satisfy information needs. Information needs arise from the awareness of a specific problem, a break in or lack of knowledge, or from uncertainty or incoherence. As researchers engage with various research projects and programmes numerous "information needs" transpire. Electronic journals present a valuable opportunity to resolve many of these information needs. The way researchers may seek to resolve their information need is adequately captured within the information seeking behaviour model outlined by Ellis (1989). A variety of methods are employed in an effort to satisfy the information need. These include chaining: following footnotes and citations; browsing: semi_directed or semi \$structured searching; differentiating: utilizing differences in information sources to filter results; monitoring: revisiting important information sources; and extracting: taking relevant information out of information sources. Following a review of various studies, Rowlands (2007) and Tenopir (2003) conclude that the general scientific community's former focus on specific journal titles has diminished as journal article browsing and directed search capabilities have increased. Furthermore, Rowlands (2007) observes that despite exhibiting shortcomings related to their search proficiency, scientists are continuing to consult a larger volume of journal articles from a wider variety of sources.

Electronic journals and related resources are assembled within electronic journal database packages. Research comparing the utility of these various database packages is haphazard. Bravo et al. (2008) sought to investigate the perceived quality and frequency of use of three common multidisciplinary database packages, ScienceDirect, Springer $\square$ Kluwer, and Wiley InterScience, at various Spanish universities during the period 2002[2005. Recorded downloads indicated the dominance of ScienceDirect, yet almost a fifth of its titles were not utilised by any of the universities under investigation. Wiley InterScience was used more frequently than Springer, though the authors note that the intensity of use was "limited". An assessment of the most popular publishers and databases at a multidisciplinary institute in India (Moghaddam \& Talawar, 2008) revealed that Elsevier (owners to the rights of ScienceDirect) was used by most scholars (64\%). Other publishers were used by significantly fewer respondents: John Wiley \& Sons (38\%); Springer[Verlag (35\%); IEEE (30\%); American Chemical Society (23\%); Cambridge University Press (17\%); Kluwer Academic Publishing (15\%); Oxford University Press (15\%); Blackwell Publishing (10\%); Taylor \& Francis (6\%); and Sage Publications (3\%).

Investigations have often centred on the medical and health fields. In a commonly cited study undertaken amongst health faculty and students of the University of Illinois Chicago (De Droote \& Dorsch 2003) over half of the users searched MEDLINE (accessible through PubMed or Ovid MEDLINE) weekly. Other databases showed significantly weaker prominence. About three quarters of respondents had never searched CINAHL; PsycINFO or (possibly most surprisingly) Web of Science. In their study of electronic journal user behaviour of high level French neuroscience researchers, nearly 97\% reported weekly use of bibliographic and full[text databases (Vibert et al., 2007). Results indicated that, after PubMed (used daily by over half of these researchers), ScienceDirect was the most widely utilised database whilst BiblioINSERM and BiblioVie were used infrequently. A study of bibliographic database use by Latin American biomedical researchers was conducted by Ospina, Herault and Cardona (2005). The 185 respondents were all published biomedical scholars representing various South American nations. The databases most used to secure

SA JnI Libs \& Info Sci 20II, 77(I) 
biomedical information in order of prominence were MEDLINE (34\%), general search engines ( $\square$ oogle, Yahoo!, and AltaVista) (16\%), onПine journals (10\%), BIREME[ILACS (6\%), BioMedNet (5\%), the databases of the Centers for Disease Control and Prevention of the United States of America (5\%), and the Cochrane Library (5\%).

An important resource used by researchers to locate relevant material is citation databases. Citation databases incorporate additional value as the impact of various papers can be assessed and cited material uncovered. There have been a number of comparisons between the Web of Science (WoS, in ISI Web of Knowledge) and Scopus citation databases. - Gavel and Iselid (2008) calculated the journal title overlap between Scopus and WoS based on the lists provided by these citation databases. Results indicated that slightly more than half $(54 \%)$ of Scopus journal titles are indexed in WoS whereas $84 \%$ of WoS journal titles are indexed in Scopus. The authors, however, found that a large number of the WoS arts and humanities journal titles ( $94 \mathrm{I}$ of their I 130) were not indexed by Scopus. Hicks and Wang's (2010) comparison of the bibliographic coverage of several journal databases and journal lists in the humanities and social sciences clearly indicated considerably greater coverage of the social sciences by Scopus. In their discussion of the JournalBase project, Dassa, Kosmopoulos and Pumain (2010) dispute the size of the coverage difference between Scopus and WoS for the social sciences. After removing all inactive titles and duplicates from their lists, these authors found that Scopus does not host many more titles than WoS. Scopus posted 6200 social science and humanities titles (about twice the number of WoS titles); but once the inactive journals, the duplicates and types of documents other than journals (colloquia, books), had been removed, only 3453 journals remained, compared to the 2864 for WoS. Closer analysis confirmed the dominance of WoS arts and humanities titles. Of the 1166 journal titles listed under arts and humanities for WoS, only 226 are included within Scopus titles. Comparisons of the respective results of citation measures reveal little difference between these databases at aggregated levels, but results may vary significantly for various disciplines, journals or institutions (Bakkalbasi et al., 2006; BarПlan, Levene \& Lin 2007; Meho \& Yang 2007; BarПlan 2008; Meho \& Rogers 2008; Archambault et al., 2009; Meho \& Sugimoto 2009; Torres_\$alinas, Lopez[Cózar \& Jiménez 2009).

From this literature review a number of important themes and objects for investigation are apparent. These include:

- Does the previously discussed preference of researchers for electronic journals apply across various fields of academic study? Is it applicable for other source types (books)?

- What methods of information seeking (chaining, browsing and monitoring) are favoured by users of electronic journals?

- There have been a number of studies that compare the utilization of various databases by specific user groups. Results are varied and haphazard. Which electronic journal databases are favoured by South African researchers? Which of these databases include most journals identified by researchers as the top journals within their particular field? How does the coverage of these top databases differ across fields?

- Which electronic journal resources (including full[text and bibliographic databases) are used to locate relevant material?

- How important are citation databases as a resource used to locate pertinent journal articles?

\section{Methodology and description of sample}

The study was based on a survey research design and data was collected through an online web based questionnaire. The overall aim was to investigate the information needs of established researchers by examining their preferred electronic information resources and search behaviour. Researchers were asked to rate the relative importance of electronic versus printed sources for their own research and the perceived importance of various components of electronic journals. They also had to list their favoured databases and subsequently comparisons are made between the top bibliographic and full $\square$ text databases. Finally, information seeking behaviour was investigated and favoured search strategies are discussed.

Purposive sampling was done by compiling a list of prominent university and Science Council researchers (e.g. researchers funded by the National Research Foundation and the South African Research Chairs Initiative) and inviting them via e-mail to participate in the web based survey. About 2026 e[mails were successfully delivered and a total of 292 completed questionnaires were captured, representing a response rate of $14 \%$.

The respondents represent a wide range of science fields, including biological sciences $(20.6 \%)$, social sciences (14.1\%), arts and humanities (II.7\%), health sciences (II.3\%), physical sciences (9.3\%), engineering sciences (8.9\%), mathematical, information and computer sciences $(7.2 \%)$, agricultural sciences $(6.9 \%)$, earth and marine sciences $(5.5 \%)$ and chemical sciences (4.5\%). Only one respondent did not specify her/his science field. No other demographic information was requested.

Since only experienced researchers were targeted, it is not surprising that nearly all respondents were involved in the supervision of masters and doctoral students and $89 \%$ of respondents reported having more than 10 years of research experience. An overwhelming majority of respondents stated that they have direct experience with online searches for information resources. Specifically, $99.7 \%$ indicated that they search online databases or request online searches when locating relevant literature/material for research purposes and $94.4 \%$ indicated that they tend to search these online databases themselves, without the help of a librarian or assistant. 


\section{Results}

\subsection{Preferred data sources for information seeking}

\section{I.I Perceived importance of electronic versus printed media}

Table I compares the relative importance of electronic information sources (electronic journals and electronic books) to printed media (printed journals and printed books and chapters in books). Electronic journals emerged as the most important information source ( $89 \%$ of respondents rated it as very important for their research) and it is also regarded as more important than printed journals (rated by $37 \%$ of respondents as very important for their research). The opposite trend is observed for books, since a greater number of respondents rated printed books and book chapters as important for their research, compared to those who rated electronic books as important.

Table I Perceived importance of electronic and printed sources for own research

\begin{tabular}{|c|c|c|c|c|c|c|}
\hline Source & Very important & Important & Neutral & $\begin{array}{c}\text { Not so } \\
\text { important }\end{array}$ & Unimportant & Total \\
\hline $\begin{array}{l}\text { Electronic Journals } \\
\text { (e[ournals) }\end{array}$ & $88.7 \%$ & $8.2 \%$ & $2.4 \%$ & $0.7 \%$ & $0 \%$ & $100 \%(n=29 \mid)$ \\
\hline Journals (Print) & $36.8 \%$ & $30.2 \%$ & $22.0 \%$ & $7.2 \%$ & $3.8 \%$ & $100 \%(n=29 \mid)$ \\
\hline $\begin{array}{l}\text { Books and Chapters } \\
\text { in Books }\end{array}$ & $28.2 \%$ & $41.1 \%$ & $22.3 \%$ & $4.2 \%$ & $4.2 \%$ & $100 \%(n=287)$ \\
\hline $\begin{array}{l}\text { Electronic books } \\
\text { (eßBooks) }\end{array}$ & $15.9 \%$ & $25.6 \%$ & $33.9 \%$ & $10.7 \%$ & $13.8 \%$ & $100 \%(n=289)$ \\
\hline
\end{tabular}

In Figures I and 2, the "very important" and "important" categories have been combined to provide a breakdown of the relative importance of journals and books by science field. As can be observed, electronic journals are rated as important across all the science fields, whereas printed journals are more likely to be rated as important by scholars in the engineering sciences (85\%), arts and humanities (82\%) and social sciences (73\%). Scholars in the fields of earth and marine sciences $(94 \%)$, arts and humanities (88\%), engineering sciences (88\%) and social sciences (85\%) were also more likely to rate printed books and chapters in books as important for research purposes. It should be noted, however, that scholars in these fields greatly depend on historical perspectives and back issues of journals are not necessarily available in electronic full[text format. Scholars in the broad field of mathematical, information and computer sciences were the most likely to rate electronic books as important for their research $(76 \%)$.

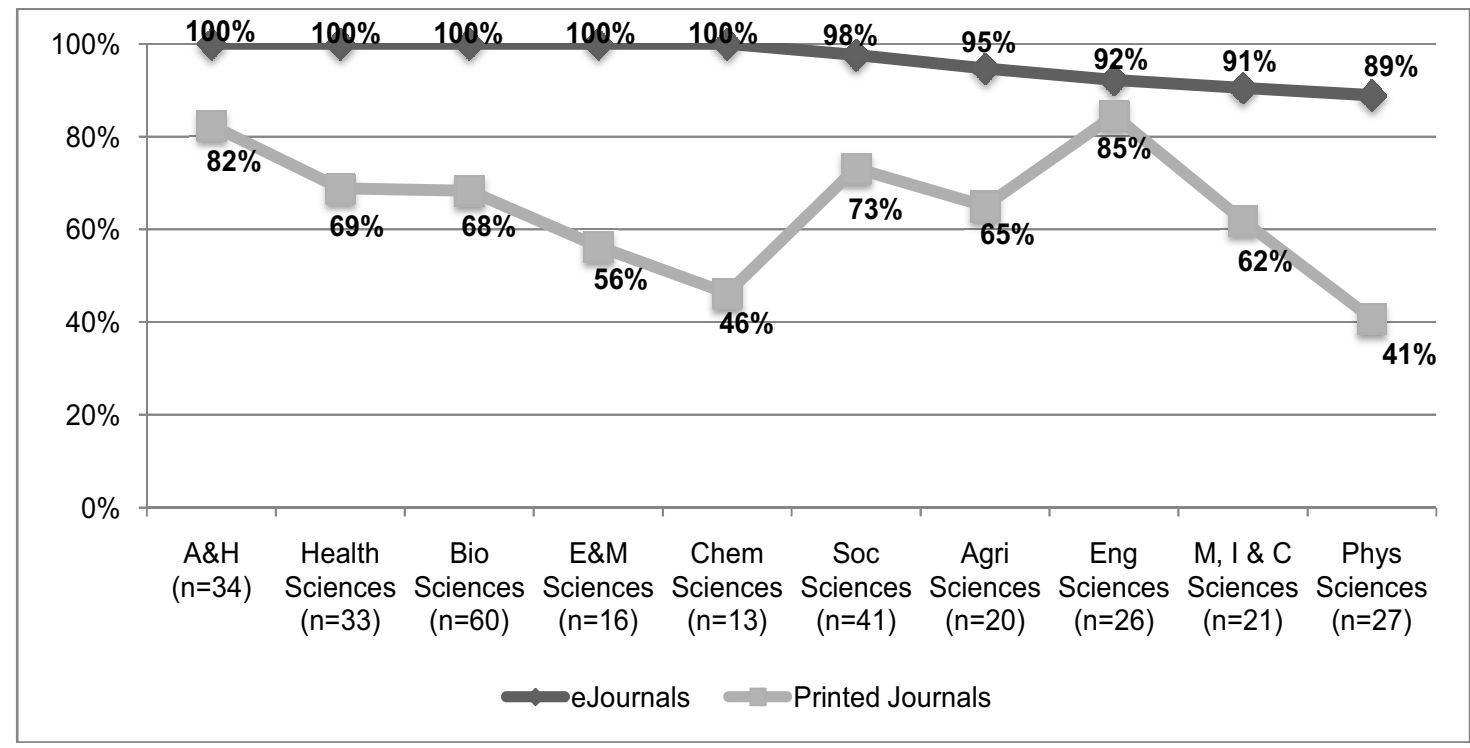

Figure 1 Percentage of respondents who rated e-Journals and printed journals as important/very important, by broad field

$\mathrm{A} \& \mathrm{H}=$ Arts and Humanities; Bio Sciences = Biological Sciences; E\&M Sciences= Earth and Marine Sciences; Chem Sciences= Chemical Sciences; Soc Sciences = Social Sciences; Agri Sciences= Agricultural Sciences; Eng Sciences= Engineering Sciences; M, I \& C Sciences= Mathematical, Information and Computer Sciences; Phys Sciences = Physical Sciences. 


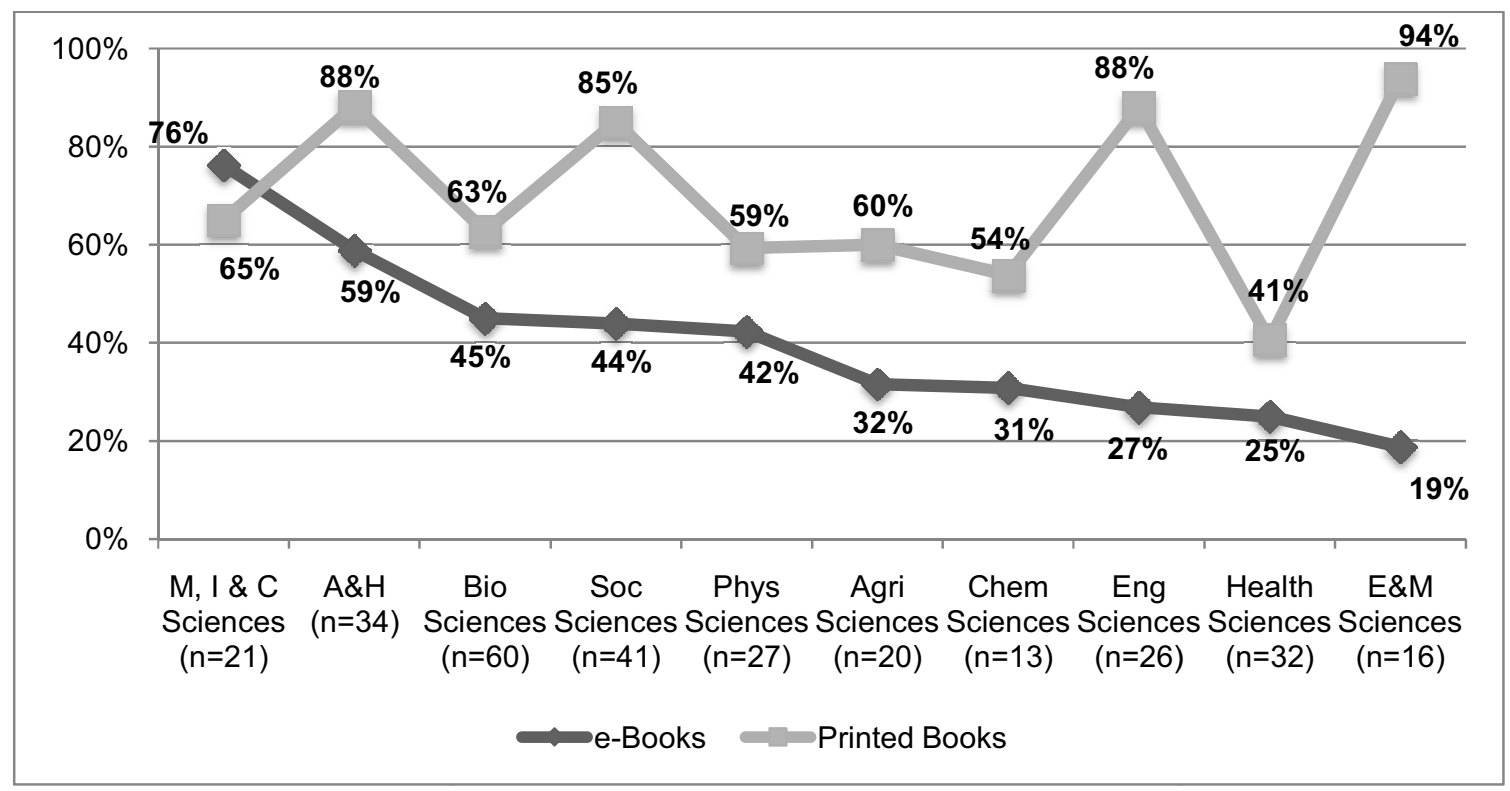

Figure 2 Percentage of respondents who rated electronic books and printed books_as important/very important, by broad field

M, I \& C Sciences = Mathematical, Information and Computer Sciences; A\&H = Arts and Humanities; Bio Sciences = Biological Sciences; Soc Sciences $=$ Social Sciences; Phys Sciences = Physical Sciences; Agri Sciences = Agricultural Sciences; Chem Sciences = Chemical Sciences; Eng Sciences $=$ Engineering Sciences; E\&M Sciences $=$ Earth and Marine Sciences.

The features of electronic journals that contribute to the fact that it is regarded as the most important data source for research purposes are examined in Table 2 . The features that researchers mostly seem to value relate to full[text availability ( $97 \%$ of respondents rated this as important or very important), abstract visibility $(92 \%)$, hyperlinks to cited articles $(88 \%)$ and the visibility of the table of contents $(75 \%)$. Thus, one could say that it is both easy access to content as well as mechanisms to easily assess the relevance of content that render journals their relative advantage over printed media.

\section{I.2 Perceived importance of various data sources}

Respondents were asked to rate the perceived importance of five data sources for their own research and for staying ahead of research developments in their specific fields. In terms of online databases, a marked percentage of respondents (58\%) rated full[text databases as very important for their research (Table 3).

In Table 4 the "important" ratings are combined with the "very important" ratings and field differences are simultaneously explored. In total, $72 \%$ of all respondents highlighted the importance of searching $\square$ oogle Scholar. There does, however, exist great field variability with regard to performing searches in $\square$ oogle Scholar, since the percentages for the two fields with the lowest and highest responses are $88 \%$ (social sciences) and $33 \%$ (chemical sciences). Very similar results are observed for $\square$ oogle searches as well as for searching full[text databases, rated by $70 \%$ of respondents as being important for their research. Once again, the field with the lowest percentage of respondents who rated $\square$ oogle searches and searching full[text databases as important for research purposes is chemical sciences ( $46 \%$ for both data sources). The field with the highest percentage of respondents who rated $\square$ oogle searches as important is arts and humanities $(85 \%)$, compared to $82 \%$ of respondents within the field of social sciences who rated searching full[text databases as important. 
Table 2 Perceived importance of components of e]ournals

\begin{tabular}{|c|c|c|c|c|c|c|}
\hline & $\begin{array}{c}\text { Very } \\
\text { important }\end{array}$ & Important & Neutral & $\begin{array}{c}\text { Not so } \\
\text { important }\end{array}$ & Unimportant & Total \\
\hline Full text availability & $88.3 \%$ & $8.9 \%$ & $2.4 \%$ & $0.3 \%$ & $0 \%$ & $\begin{array}{c}100 \% \\
(n=291)\end{array}$ \\
\hline Article abstracts & $65.5 \%$ & $26.5 \%$ & $7.3 \%$ & $0 \%$ & $0.7 \%$ & $\begin{array}{c}100 \% \\
(n=287)\end{array}$ \\
\hline Direct linking to cited articles (by clicking on it) & $52.2 \%$ & $36.0 \%$ & $7.6 \%$ & $2.1 \%$ & $2.1 \%$ & $\begin{array}{c}100 \% \\
(n=289)\end{array}$ \\
\hline Table of contents & $46.3 \%$ & $29.1 \%$ & $15.8 \%$ & $3.9 \%$ & $4.9 \%$ & $\begin{array}{c}100 \% \\
(n=285)\end{array}$ \\
\hline Direct linking to authors' e[mail (by clicking on it) & $29.3 \%$ & $32.1 \%$ & $21.0 \%$ & $9.7 \%$ & $7.9 \%$ & $\begin{array}{c}100 \% \\
(n=290)\end{array}$ \\
\hline Alerting services & $20.6 \%$ & $27.9 \%$ & $31.7 \%$ & $11.8 \%$ & $8.0 \%$ & $\begin{array}{c}100 \% \\
(n=287)\end{array}$ \\
\hline Screen layout (interface) & $13.1 \%$ & $31.1 \%$ & $43.3 \%$ & $5.9 \%$ & $6.6 \%$ & $\begin{array}{c}100 \% \\
(n=289)\end{array}$ \\
\hline Added data files/ supplements (e.g. in Excel, Word) & $9.4 \%$ & $24.7 \%$ & $38.5 \%$ & $16.0 \%$ & $11.5 \%$ & $\begin{array}{c}100 \% \\
(n=288)\end{array}$ \\
\hline Contain multimedia information & $4.2 \%$ & $12.5 \%$ & $52.4 \%$ & $16.0 \%$ & $14.9 \%$ & $\begin{array}{c}100 \% \\
(n=288)\end{array}$ \\
\hline $\begin{array}{l}\text { Discussion platforms, possibility to comment on } \\
\text { articles online }\end{array}$ & $1.7 \%$ & $9.3 \%$ & $43.6 \%$ & $23.2 \%$ & $22.1 \%$ & $\begin{array}{c}100 \% \\
(n=289)\end{array}$ \\
\hline
\end{tabular}

Table 3 Perceived importance of data sources for own research and/or for staying ahead of research developments

\begin{tabular}{|c|c|c|c|c|c|c|c|}
\hline & $\begin{array}{c}\text { Very } \\
\text { important }\end{array}$ & Important & Neutral & $\begin{array}{c}\text { Not so } \\
\text { important }\end{array}$ & Unimportant & $\begin{array}{l}\text { Don't know } \\
\text { what it is }\end{array}$ & Total \\
\hline $\begin{array}{l}\text { Searching full[text databases } \\
\text { (i.e. databases that contain full } \\
\text { articles or complete contents } \\
\text { of chapters, reports or other } \\
\text { materials) }\end{array}$ & $58.1 \%$ & $11.6 \%$ & $10.8 \%$ & $3.2 \%$ & $6.1 \%$ & $10.1 \%$ & $\begin{array}{c}100 \% \\
(n=277)\end{array}$ \\
\hline Searching $\square$ oogle Scholar & $43.0 \%$ & $29.0 \%$ & $16.1 \%$ & $2.1 \%$ & $3.1 \%$ & $6.6 \%$ & $\begin{array}{c}100 \% \\
(n=286)\end{array}$ \\
\hline $\begin{array}{l}\text { Searching across databases } \\
\text { using a meta[database/plat } \square \\
\text { form (e.g. MetaLib) available } \\
\text { at your university library } \\
\text { website }\end{array}$ & $36.4 \%$ & $17.5 \%$ & $18.2 \%$ & $6.3 \%$ & $7.0 \%$ & $14.7 \%$ & $\begin{array}{c}100 \% \\
(n=286)\end{array}$ \\
\hline Searching $\square$ oogle & $33.6 \%$ & $36.3 \%$ & $16.3 \%$ & $7.3 \%$ & $4.2 \%$ & $2.4 \%$ & $\begin{array}{c}100 \% \\
(n=289)\end{array}$ \\
\hline $\begin{array}{l}\text { Searching bibliographic } \\
\text { databases (containing only } \\
\text { abstracts or citations of } \\
\text { articles, not full publications) }\end{array}$ & $32.1 \%$ & $12.8 \%$ & $23.8 \%$ & $8.7 \%$ & $14.0 \%$ & $8.7 \%$ & $\begin{array}{c}100 \% \\
(n=265)\end{array}$ \\
\hline
\end{tabular}


Table 4 Percentages of respondents by broad field who rated a data source as important/very important

\begin{tabular}{|c|c|c|c|c|}
\hline Data Source & $\begin{array}{l}\text { All respondents } \\
\text { in all fields }\end{array}$ & $\begin{array}{c}\text { Field with smallest } \\
\text { percentage of } \\
\text { respondents who rated a } \\
\text { data source as important/ } \\
\text { very important }\end{array}$ & $\begin{array}{c}\text { Field with largest } \\
\text { percentage of } \\
\text { respondents who rated a } \\
\text { data source as important/ } \\
\text { very important }\end{array}$ & $\begin{array}{l}\text { Number of fields in which } \\
50 \% \text { or more of the } \\
\text { respondents rated a data } \\
\text { source as important/ } \\
\text { very important }\end{array}$ \\
\hline Searching $\square$ oogle Scholar & $72.0 \%(n=286)$ & $\begin{array}{c}\text { Chemical Sciences } \\
33.3 \%(n=12)\end{array}$ & $\begin{array}{l}\text { Social Sciences } \\
87.8 \%(n=4 I)\end{array}$ & 9 \\
\hline Searching $\square$ oogle & $69.9 \%(n=289)$ & $\begin{array}{c}\text { Chemical Sciences } \\
46.2 \%(n=13)\end{array}$ & $\begin{array}{l}\text { Arts and Humanities } \\
84.8 \%(n=33)\end{array}$ & 9 \\
\hline $\begin{array}{l}\text { Searching full[text databases } \\
\text { (i.e. databases that contain full } \\
\text { articles or complete contents } \\
\text { of chapters, reports or other } \\
\text { materials) }\end{array}$ & $69.7 \%(n=277)$ & $\begin{array}{c}\text { Chemical Sciences } \\
46.2 \%(n=13)\end{array}$ & $\begin{array}{l}\text { Social Sciences } \\
82.1 \%(n=39)\end{array}$ & 9 \\
\hline $\begin{array}{l}\text { Searching across databases } \\
\text { using a meta_database/ } \\
\text { platform (e.g. MetaLib) } \\
\text { available at your university } \\
\text { library website }\end{array}$ & $53.9 \%(n=286)$ & $\begin{array}{l}\text { Physical Sciences } \\
36.0 \%(n=25)\end{array}$ & $\begin{array}{c}\text { Math, Info and Comp } \\
\text { Sciences } \\
66.7 \%(n=21)\end{array}$ & 6 \\
\hline $\begin{array}{l}\text { Searching bibliographic } \\
\text { databases (containing only } \\
\text { abstracts or citations of } \\
\text { articles, not full publications) }\end{array}$ & $44.9 \%(n=265)$ & $\begin{array}{l}\text { Earth and Marine Sciences } \\
\qquad 26.7 \%(n=15)\end{array}$ & $\begin{array}{c}\text { Chemical Sciences } \\
53.8 \%(n=13)\end{array}$ & 3 \\
\hline
\end{tabular}

* Math, Info and Comp Sciences = Mathematical, Information and Computer Sciences

The bibliographic and full[text databases mostly used by the respondents to search for relevant literature for research purposes are specified in Table 5. Three publishing houses dominate the results: Elsevier (50\%), Thomson Reuters (27\%) and EBSCOhost (21\%). EBSCOhost (21\%) and Elsevier's ScienceDirect database (27\%) are the main full[text sources. The main bibliographic databases are ISI Web of Knowledge by Thomson Reuters (24\%) and Scopus by Elsevier (17\%).

Table 5 Main databases (bibliographic and full[text) used by respondents

\begin{tabular}{lcc}
\hline Databases & Count & Percentage (out of 209) * \\
EBSCOhost & 43 & $20.6 \%$ \\
Elsevier & 105 & $50.1 \%$ \\
Elsevier $\square$ ScienceDirect & 57 & $27.2 \%$ \\
Elsevier $\square$ Scopus & 36 & $17.2 \%$ \\
Elsevier $\square$ Not specified & 5 & $2.4 \%$ \\
Elsevier $\square$ Other & 7 & $3.3 \%$ \\
JSTOR & 32 & $15.3 \%$ \\
Medline & 11 & $5.3 \%$ \\
PubMed & 50 & $23.9 \%$ \\
Sabinet Online & 14 & $6.7 \%$ \\
SpringerLink & $9 \%$ \\
Thompson Reuters & 19 & $27.1 \%$ \\
Thompson Reuters $\square I S I$ Web of Knowledge $\square$ Web of Science & 57 & $14.8 \%$ \\
Thompson Reuters $\square I S I$ Web of Knowledge $\square$ Not specified & 31 & $9 \%$ \\
Thompson Reuters $\square$ Other & 19 & $3.3 \%$ \\
Wiley & 7 & $5.7 \%$ \\
\hline * 209 of the 292 respondents listed at least one database. & 12 &
\end{tabular}

Respondents were furthermore requested to list the titles of up to five scientific or scholarly journals that they most frequently read/use in their research. Altogether 274 of the 292 respondents listed at least one journal title, and the total 
number of journals specified amounted to 870. Table 6 provides a field\$pecific breakdown of the inclusion of these journals in four selected databases (WoS, Scopus, EBSCOhost and ScienceDirect). Both EBSCOhost and ScienceDirect cover less than $50 \%$ of the "top" journals in all fields, with as little as $1 \%$ in the arts and humanities (ScienceDirect) and $3 \%$ in chemical sciences (EBSCOhost). ScienceDirect has significantly better journal coverage than EBSCOhost in four fields: agricultural sciences; chemical sciences; mathematical, information and computer sciences; and physical sciences. EBSCOhost, on the other hand, seems to include significantly more "top" journals than ScienceDirect in the arts and humanities, economic and management sciences, health sciences and social sciences. Moreover, in three fields the difference in coverage between the two databases does not exceed 5\%, namely biological sciences, earth and marine sciences, and engineering sciences. As far as the two bibliographic databases are concerned, Scopus displays a marginally better coverage than WoS in all fields, with the exception of economic and management sciences.

Table 6 Coverage of top journals in two bibliographic and two full[text databases, by field

\begin{tabular}{|c|c|c|c|c|}
\hline \multirow{2}{*}{ Field } & \multicolumn{2}{|c|}{ Bibliographic } & \multicolumn{2}{|c|}{ Full-text } \\
\hline & WoS & Scopus & EBSCOhost & ScienceDirect \\
\hline \multicolumn{5}{|c|}{ Agricultural Sciences } \\
\hline (8I journals) & $90 \%$ & $95 \%$ & $25 \%$ & $40 \%$ \\
\hline \multicolumn{5}{|c|}{ Arts \& Humanities } \\
\hline ( 120 journals) & $52 \%$ & $57 \%$ & $28 \%$ & $1 \%$ \\
\hline \multicolumn{5}{|c|}{ Biological Sciences } \\
\hline (182 journals) & $92 \%$ & $93 \%$ & $24 \%$ & $29 \%$ \\
\hline \multicolumn{5}{|c|}{ Chemical Sciences } \\
\hline (34 journals) & $88 \%$ & $94 \%$ & $3 \%$ & $44 \%$ \\
\hline \multicolumn{5}{|c|}{ Earth \& Marine Sciences } \\
\hline (59 journals) & $98 \%$ & $100 \%$ & $36 \%$ & $32 \%$ \\
\hline \multicolumn{5}{|c|}{ Economic \& Management Sciences* } \\
\hline (44 journals) & $84 \%$ & $80 \%$ & $45 \%$ & $23 \%$ \\
\hline \multicolumn{5}{|c|}{ Engineering Sciences } \\
\hline (90 journals) & $77 \%$ & $82 \%$ & $28 \%$ & $28 \%$ \\
\hline \multicolumn{5}{|c|}{ Health Sciences } \\
\hline (I04 journals) & $90 \%$ & $96 \%$ & $27 \%$ & $19 \%$ \\
\hline \multicolumn{5}{|c|}{ Mathematical, Information \& Computer Sciences } \\
\hline (62 journals) & $74 \%$ & $82 \%$ & $19 \%$ & $29 \%$ \\
\hline \multicolumn{5}{|c|}{ Physical Sciences } \\
\hline (73 journals) & $89 \%$ & $96 \%$ & $18 \%$ & $34 \%$ \\
\hline \multicolumn{5}{|l|}{ Social Sciences } \\
\hline (98 journals) & $81 \%$ & $90 \%$ & $34 \%$ & $12 \%$ \\
\hline \multicolumn{5}{|l|}{ All fields } \\
\hline (870 journals) & $82 \%$ & $86 \%$ & $26 \%$ & $23 \%$ \\
\hline
\end{tabular}

*The science field categories in the table above are based on the subject area of the journals and not on the particular science fields of the individual respondents. The inclusion of the category 'Economic and Management Sciences', was done to provide a more detailed breakdown of the journals specified by the respondents.

\subsection{Selected methods of information seeking}

The analysis now shifts to methods of seeking and locating relevant knowledge resources for research purposes. The relative importance of three search methods is examined in Table 7, where results illustrate to what extent respondents regard the search methods as important and very important (categories are combined) for their own research or for staying ahead of research developments.

Across all science fields, following bibliographic references within journal articles or books was regarded as the most important strategy of the three search methods. It is worth noting that all of the respondents within the field of earth and marine sciences regard browsing through recent issues of journals with titles relevant to their research, as an important strategy for locating relevant information. 
Table 7 Respondents who rated three search methods as important/very important, by broad fields

\begin{tabular}{lll}
\hline $\begin{array}{c}\text { Following bibliographic references within } \\
\text { articles, books etc. }\end{array}$ & $\begin{array}{c}\text { Browsing through recent issues of a } \\
\text { relevant journal title }\end{array}$ & $\begin{array}{c}\text { Relying on alerting services (based on } \\
\text { personal profile) }\end{array}$ \\
\hline Engineering Sciences & $\begin{array}{l}\text { Earth and Marine Sciences } \\
100 \%(n=16)\end{array}$ & $\begin{array}{l}\text { Chemical Sciences } \\
61.5 \%(n=13)\end{array}$ \\
$96 \%(n=25)$ & Arts and Humanities & Earth and Marine Sciences \\
Math, Info and Comp Sciences & $88.2 \%(n=34)$ & $60 \%(n=15)$ \\
$95.2 \%(n=21)$ & Physical Sciences & Health Sciences \\
Biological Sciences & $85.2 \%(n=27)$ & $51.5 \%(n=33)$ \\
$93.3 \%(n=60)$ & Biological Sciences & Biological Sciences \\
Social Sciences & $83.3 \%(n=60)$ & $50.8 \%(n=59)$ \\
$92.7 \%(n=41)$ & Social Sciences & Social Sciences \\
Arts and Humanities & $82.9 \%(n=4 I)$ & $46.2 \%(n=39)$ \\
$91.2 \%(n=34)$ & Engineering Sciences & Agricultural Sciences \\
Physical Sciences & $80 \%(n=25)$ & $45 \%(n=20)$ \\
$88.5 \%(n=26)$ & Chemical Sciences & Math, Info and Comp Sciences \\
Health Sciences & $76.9 \%(n=13)$ & $35 \%(n=20)$ \\
$87.9 \%(n=33)$ & Health Sciences & Physical Sciences \\
Earth and Marine Sciences & $75.8 \%(n=33)$ & $30.8 \%(n=26)$ \\
$87.5 \%(n=16)$ & Math, Info and Comp Sciences & Arts and Humanities \\
Agricultural Sciences & $71.4 \%(n=21)$ & $29 \%(n=31)$ \\
$85 \%(n=20)$ & Agricultural Sciences & Engineering Sciences \\
Chemical Sciences & $60 \%(n=20)$ & $23.1 \%(n=26)$ \\
$84.6 \%(n=13)$ & All fields & All fields \\
All fields & $\mathbf{8 1 \%}(n=290)$ & $\mathbf{4 2 . 9 \% ~}(n=282)$ \\
$91 \%(n=289)$ & &
\end{tabular}

* Math, Info and Comp Sciences = Mathematical, Information and Computer Sciences

\section{Discussion and conclusion}

These findings will now be discussed in relation to the themes and objects for investigation emphasized following the literature review. The aim is to present an overview of the use of electronic knowledge resources, particularly electronic journal resources, by distinguished South African researchers and to underline notable points for consideration.

5.1 The preferred resource format: electronic vs. print

Various studies have confirmed the growing prominence and importance of electronic journals for academic researchers. It is therefore not surprising that the vast majority $(97 \%)$ of researchers surveyed in this study also indicated that electronic journals are an important source for their own research. Also in accordance with the aforementioned studies, it was found that the perceived importance of print journals, though still significant, has waned (only about two thirds of the researchers rated print journals an important resource). Though electronic journals (as opposed to print journals) are consistently rated important by a greater number of researchers across all fields, the relative importance of print journals varies across fields. Researchers in the field of engineering sciences (85\%), arts and humanities (82\%) and social sciences (73\%) generally rated print journals as important whereas researchers in the field of the physical $(41 \%)$ and chemical sciences $(46 \%)$ were less inclined to rate print journals as important. This discrepancy may be attributed to the need in the former fields for older material not electronically available. It is interesting to note that despite the considerable preference for electronic journals over print journals, most researchers still prefer printed copies of books to electronic books. This may again be attributed to the relatively limited material electronically available. The only exception was within the field of mathematical, information and computer sciences where a greater number of researchers rated electronic books as important.

5.2 Methods of information seeking favoured by users of electronic journals

The most popular methods of information seeking preferred by $91 \%$ of respondents was following bibliographic references within articles, books, etc. (chaining) followed by browsing through recent issues of a relevant journal (included by $81 \%$ of the researchers). Relying on alerting services (monitoring) was preferred by significantly fewer researchers (only 43\%). This is in accordance with international trends. The literature reviewed revealed that researchers prize functions within electronic databases that facilitate faster and more effective location of, and indicate availability of, full $\square$ 
text articles and abstracts (chaining and browsing functions). Discussion platforms and alerts indicating new publications are considered less important (monitoring functions).

\subsection{Comparison of databases favoured by researchers}

EBSCOhost $(21 \%)$ and ScienceDirect $(27 \%)$ were the two most popular full text databases amongst leading researchers. It is important to note that both EBSCOhost and ScienceDirect cover less than $50 \%$ of the "top" journals in all fields (i.e. journals specified by respondents as the most relevant for their research), with ScienceDirect covering as little as $1 \%$ in the arts and humanities and EBSCOhost only $3 \%$ in chemical sciences. ScienceDirect has significantly better coverage than EBSCOhost of the "top" journals in four fields: agricultural sciences; chemical sciences; mathematical, information and computer sciences; and physical sciences. EBSCOhost, on the other hand, seems to include significantly more "top" journals than ScienceDirect in the arts and humanities, economic and management sciences, health sciences and social sciences. There are a number of concerns that are related to the quality of journal articles found within EBSCOhost. Whereas ScienceDirect is owned by a publisher and their publications are subject to peer review processes, EBSCOhost

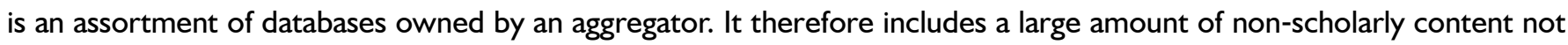
always subject to peerfreview processes. Furthermore, it has been contended that EBSCOhost content duplicates the content of other publishers; many embargoes prevent access to the most recent findings; and holdings are unpredictable as titles may be removed from the collection at any point. It was also one of the first databases acquired in South Africa and this may therefore have attributed to its widespread adoption.

\subsection{Electronic journal resources used to locate relevant material}

The importance of full text availability is emphasized by the large number of researchers that preferred searching fulltext databases to locate relevant material. Searches that run across databases/platforms (e.g. MetaLib, \oogle Scholar and Doogle) were rated less favourably and searching bibliographic databases was considered least important (rated important by only $40 \%$ of the researchers). $\square$ oogle Scholar was rated the most popular search engine across databases and was favoured over "academic" databases/platform searches like MetaLib.

\subsection{Importance of citation databases}

The two top bibliographic databases were the citation databases ISI Web of Knowledge by Thomson Reuters (favoured by $24 \%$ of researchers) and Scopus by Elsevier (listed by $17 \%$ ). Both these bibliographic databases cover over $80 \%$ of the top rated journals listed by the researchers. It has been suggested that in the fields of the life, physical and health sciences, coverage by Scopus is superior. This study revealed that the two databases have a similar coverage for the top biological science and earth and marine science journals listed by researchers. Differences in coverage between the physical ( $89 \%$ for WoS compared to $96 \%$ for Scopus) and health science ( $90 \%$ for WoS compared to $96 \%$ for Scopus) journals is, however, more significant. The literature review revealed that Scopus provides more extensive coverage of the social sciences. The results of this study also indicate that a greater number of top rated journal titles are covered by Scopus ( $90 \%$ compared to $81 \%$ for WoS). Conversely the literature indicated that coverage of the arts and humanities by Scopus was inferior. Despite this a greater number of the top journals is indexed within Scopus (57\% compared to $54 \%$ for WoS). It should, however, be emphasized that the retrospective coverage (before 1996) by Scopus is problematic.

\section{Conclusion: points for consideration}

$\square$ iven these findings, it appears that the preference of researchers to utilize search functions within the full text databases EBSCOhost and ScienceDirect to locate relevant material may significantly limit the acquisition of relevant material. The vast majority of top rated journals are covered by the citation databases ISI Web of Knowledge and Scopus: however, these data sources are the least preferred sources used to locate relevant material. The most popular full text databases (EBSCOhost and ScienceDirect) cover less than half of the top rated journals whereas WoS and Scopus both cover over $80 \%$ of these top journals. The citation databases have the added utility of assessing the impact of articles and citations can subsequently be followed up. It therefore would seem prudent that researchers make more use of these resources. The prominence of $\square$ oogle and $\square$ oogle Scholar allude to the importance of federated searches across databases. These services have, however, been criticized for their non transparency and lack of scientific credibility. It is therefore expected (and necessary) that the prominence of other federated and academic oriented search engines (e.g. MetaLib) should increase as their search functions improve.

\section{Acknowledgements}

This article forms part of an investigation into the electronic information needs of academic staff and researchers within the research councils in South Africa. The investigation was commissioned by the Scholarly Publishing Unit (SPU) at the Academy of Science of South Africa (ASSAf), and undertaken by the Centre for Research on Evaluation, Science and Technology (CREST) at Stellenbosch University. The authors would like to express their gratitude to the senior 
researcher at CREST, Mr. Nelius Boshoff, for his invaluable guidance, as well as to the director of CREST, Prof. Johann Mouton, for his contribution to earlier drafts.

\section{References}

Archambault, E., Campbell, D., Dringas, Y. and Larivière, V. 2009. Comparing bibliometric statistics obtained from the Web of Science and Scopus. Journal of the American Society for Information Science and Technology, 60(7): I320-1326.

Bakkalbasi, N., Bauer, K., $\square$ lover, J. and Wang, L. 2006. Three options for citation tracking: $\square$ oogle Scholar, Scopus and Web of Science. Biomedical Digital Libraries, 3(7):498[5 12.

BarDlan, J. 2008. Which h[index? $\square$ A comparison of Web of Science, Scopus and $\square$ oogle Scholar. Scientometrics, 74(2):257[27I.

BarDlan, J., Levene, M. and Lin A. 2007. Some measures for comparing citation databases. Journal of Informetrics, I (I):26 B4.

BarПlan, J., Peritz, B.C. and Wolman, Y. 2003. A survey on the use of electronic databases and electronic journals accessed through the web by the academic staff of Israeli universities. The Journal of Academic Librarianship, 29(6):346 B6I.

Bravo, B. R., Díez, M. L. A., Almuzara, L. B. and Suárez, M. A. M. 2008. Patterns of use of electronic journals in Spanish University Libraries. Serials Review, 34:I I5-128.

Dassa, M., Kosmopoulos, C., and Pumain, D. 2010. JournalBase $\square$ A comparative international study of scientific journal databases in the Social Sciences and the Humanities (SSH). CyberGeo. [Online]. http://cybergeo.revues.org/ index22862.html?lang =fr. Accessed 20 June 2010.

De $\square$ roote, S.L. and Dorsch, J.L. 2003. Measuring use patterns of online journals and databases. Journal of the Medical Library Association, $91(2): 23 \mathrm{I}-240$.

Dillon, I. F. \& Hahn, K. L. 2002. Are researchers ready for the electronic only journal collection? Results of a survey at the University of Maryland. Libraries and the Academy, 2:375-390.

Ellis, D.A. 1989. A behavioral approach to information retrieval system design. Journal of Documentation, 5:I7I [2I 2.

Davel, Y. and Iselid, L. 2008. Web of Science and Scopus: a journal title overlap study. Online Information Review, 32(I):8[2I.

Hicks, D.and Wang, J. 2010. Coverage and overlap of the new social science and humanities journal lists. [Online]. http:// works.bepress.com\%2Fcgi\%2Fviewcontent.cgi\%3Farticle\%3DI021\%26context\%3Ddiana_hicks. Accessed I7 August 2010.

Institute for the Future. 2002. Final Synthesis Report of the E[ournal User Study. [Online]. http://ejust.stanford.edu/SR $\square$ 786. ejustfinal.html. Accessed 20 March 2010.

Meho, L. I. and Rogers, Y. 2008. Citation counting, citation ranking, and h[index of human computer interaction researchers: a comparison of Scopus and Web of Science. Journal of the American Society for Information Science and Technology, 59(I I): I 7 I I $\square$ 1726.

Meho, L. I. and Sugimoto, C. R. 2009. Assessing the scholarly impact of information studies: a tale of two citation databases $\square$ Scopus and Web of Science. Journal of the American Society for Information Science and Technology, 60(I2):2499 [2508.

Meho, L. I. and Yang, K. 2007. Impact of data sources on citation counts and rankings of LIS faculty: Web of Science versus Scopus and Doogle Scholar. Journal of the American Society for Information Science and Technology, 58(I 3):2 105 [2 I I 5.

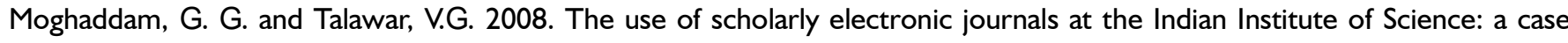
study in India. Interlending \& Document Supply, 36(I): I5-29.

Monopoli, M., Nicholas, D., Deorgiou, P. \& Korfitai, M. 2002. A user[oriented evaluation of digital libraries: case study of the electronic journals' service of the Library and Information Service of the University of Patras, Dreece. ASLIB Proceedings, 54:103-117.

Odongo, R. I. \& Mostert, J. 2006 Information seeking behaviour: a conceptual framework. South African Journal of Libraries \& Information Science, 72(3): I45口58.

Ospina, E. —., Herault, L. R. and Cardona, A. F. 2005. The use of bibliographic databases by Spanish\$peaking Latin American biomedical researchers: a cross\$lectional study. Rev Panam Salud Publica, 17(4):230[236.

Rogers, S. A. 200I. Electronic journals usage at Ohio State University. College \& Research Libraries, 62:25-34.

Rowlands, I. 2007. Electronic journals and user behavior: a review of recent research. Library \& Information Science Research, 29:369-396.

Tenner, E. \& Zheng, Y. Y. 1999. End user acceptance of electronic journals: a case study from a major academic research library. Technical Services Quarterly, 17:1-14.

Tenopir, C. 2003. Use and users of electronic library resources: an overview and analysis of recent research studies. Available: http://www.clir.org/pubs/reports/pub/20/pub/20.pdf. Accessed I5 May 2010.

Tenopir, C., King, D. W., Boyce, P., Mitchell, M, Drayson, M, Zhang, Y. and Ebuen, M. 2003. Patterns of journal use by scientists through three evolutionary phases. DZib Magazine. 9(5).

Torres\$alinas, D., Lopez[Cózar, E. D. and Jiménez[Contrera, E. 2009. Ranking of departments and researchers within a university using two different databases: Web of Science versus Scopus. Scientometrics, (3):763-776.

Vibert, N., Rouet, J. F. Ros, C., Ramond, M. and Deshoullieres, B. 2007. The use of online electronic information resources in scientific research: the case of neuroscience. Library \& Information Science Research, 29:508-532.

Voorbij, H and Ongering, H. 2008. The use of electronic journals by Dutch researchers: a descriptive and exploratory study. Journal of Academic Librarianship, 34(3):239[247. 